\title{
Prevalence of High-Risk Groups for Gastric Carcinoma - A Biopsy Finding
}

\author{
Geetikc KC $C^{1}$, Shiva Raj KC $C^{2}$ Purnima Gyawali \\ ${ }^{1}$ Department of Pathology, KIST Medical College, Lalitpur, Nepal. \\ ${ }^{2}$ Department of Pathology, Patan Academy of Health Sciences, Lalitur, Nepal. \\ ${ }^{3}$ Medical Student, KIST Medical College, Lalitpur, Nepal.
}

\section{ABSTRACT}

Introduction: Gastric carcinoma is leading cause of death world wide including Nepal. The 5 years survival rate of gastric carcinoma $(25 \%)$ is drastically decreased compared to early gastric cancers $(90-90 \%)$ hence implying the need for early detection. Atrophic gastritis and intestinal metaplasia are considered as major high-risk factors and has a precancerous lesion along with Helicobacter pylori. This study tries to look at the distribution of atrophy and intestinal metaplasia across age and gender and their occurrence in Helicobacter pylori positive cases.

Materials and Methods: It is Cross-sectional study of a retrospectively collected data at KIST medical college and GRP poly clinic private limited from April 2008 till March 2018. Total of 10,683 cases were included. The slides were stained with Hematoxilin and Eosin stain and Giemsa stain and evaluated by two pathologists. Statistical analysis was done using SPSS vs 21.

Results: Total numbers of cases studied were 10,683 with male to female ratio of $1.04: 1$. The most common age group of the study was $18-40$ years $(n=6206 ; 58.8 \%)$. Atrophy was seen in $81(0.8$ \%) cases, Intestinal metaplasia in $298(2.8 \%)$ cases and Helicobacter Pylori was positive in 4459 $(42.2 \%)$ cases. The incidence of atrophic gastritis was more in H. pylori positive group $54(0.5 \%)$ group where as intestinal metaplasia was more in H. pylori negative 190(1.8\%) group.

Conclusions: Atrophic gastritis and intestinal metaplasia, high-risk factors for gastric carcinoma, were not the common findings. Atrophic gastritis was seen in $0.8 \%$ and intestinal metaplasia was seen in $2.8 \%$ of the total study population.

Keywords: Atrophic; Carcinoma; Gastritis; Intestinal; Metaplasia; Precancer
Copyright: This is an open-access article distributed under the terms of the Creative Commons Attribution 4.0 International License, which permits unrestricted use, distribution, and reproduction in any medium, provided the original author and source are credited.

\section{Correspondence:}

Dr. Geetika K C, MBBS, MD

Lecturer, Department of Pathology

KIST Medical College, Imadole, Lalitpur, Nepal ORCID ID: 0000-0003-4343-2586

Email: geetikakc@hotmail.com

\section{Submitted: $19^{\text {th }}$ September 2018}

Accepted: $15^{\text {th }}$ October 2018

Published: $1^{\text {st }}$ December 2018

\section{Conflict of Interest: None} Sources of Support: None

Citation: KC Geetika, KC Shiva R, Gyawali P. Prevalence of high-risk groups for gastric carcinoma - a biopsy finding. Nep Med J 2018;1:82-5. DOI: 10.3126/nmj.v\%vi\%i.21600

\section{INTRODUCTION}

Gastric carcinoma is the fourth leading cause of cancer deaths and has high incidence in Eastern Asia. ${ }^{1}$ It is the sixth leading cause of morbidity, worldwide, while it is the second most common cause of death preceded by lung cancer. ${ }^{2}$ In Nepal, Gastric cancer is the $5^{\text {th }}$ most common cancer with 1546 recorded new cases in 2018. According to 2018 data, it is the $5^{\text {th }}$ most common cancer and 3rd most common cause of cancer related death in Nepal. ${ }^{3}$ It is seen that, the 5 years survival among gastric carcinoma patients is only 25 percent. In stark contrast to that, the early gastric cancers (EGC) have a 5 years survival rate of $90-95 \% 4-6$ implying detection at the later stage of the disease. ${ }^{7}$

Risk factors for gastric carcinoma include Helicobacter pylori infection, smoking, alcohol, salt intake, family history of gastric cancer, atrophic gastritis (AG) and intestinal metaplasia (IM). ${ }^{8}$ The later two, intestinal metaplasia and atrophic gastritis, are the consequence of prolonged exposure to Helicobacter Pylori and other irritants. Both, atrophy and intestinal metaplasia are considered two premalignant conditions. ${ }^{9,10}$ Transformation from atrophy and intestinal metaplasia into carcinoma requires prolonged continual exposure to the carcinogens. Hence, detection of gastric atrophy and intestinal metaplasia and timely management of the condition decreases the incidence of gastric cancer.

AG and IM are reported in a regular basis in the gastric biopsy specimen particularly because the updated Sydney system of classification is followed world wide. Both AG and IM have 
Table 1: Distribution of atrophy and intestinal metaplasia according to the gender

\begin{tabular}{|c|c|c|c|c|c|c|}
\hline \multirow[t]{2}{*}{ Gender } & \multicolumn{2}{|c|}{ Atrophy } & \multirow[t]{2}{*}{ P value } & \multicolumn{2}{|c|}{ Intestinal Metaplasia } & \multirow[t]{2}{*}{ P value } \\
\hline & Positive & Negative & & Positive & Negative & \\
\hline Male & $39(0.36 \%)$ & 5326 & \multirow[t]{3}{*}{$>0.05$} & $124(1.17 \%)$ & 5241 & \multirow[t]{3}{*}{$<0.01$} \\
\hline Female & $42(0.39 \%)$ & 5148 & & $174(1.64 \%)$ & 5016 & \\
\hline Total & $81(0.8 \%)$ & $10474(99.2 \%)$ & & $298(2.8 \%)$ & $10257(97.2 \%)$ & \\
\hline
\end{tabular}

Table 2: Distribution of Atrophy and intestinal metaplasia in relation to H.pylori infection.

\begin{tabular}{ccccc}
\hline H. pylori & \multicolumn{2}{c}{ Atrophy } & \multicolumn{2}{c}{ Intestinal Metaplasia } \\
\hline & Positive & Negative & Positive & Negative \\
Positive & $54(0.5 \%)$ & $4405(0.98 \%)$ & $108(1 \%)$ & $4351(0.42 \%)$ \\
Negative & $27(0.25 \%)$ & $6069(0.57 \%)$ & $190(1.8 \%)$ & $5906(0.56 \%)$ \\
Total & $81(0.8 \%)$ & $10474(99 \%)$ & $298(2.8 \%)$ & $10257(97 \%)$
\end{tabular}

Table 3: Distribution of Atrophy and Intestinal metaplasia according to age group.

\begin{tabular}{ccc}
\hline Age group (years) & $\begin{array}{c}\text { Intestinal } \\
\text { metaplasia }\end{array}$ & Atrophy \\
\hline $\mathbf{0 - 1 8}$ & $7(0.66 \%)$ & 0 \\
$\mathbf{1 8 - 4 0}$ & $142(1.34 \%)$ & $44(0.41 \%)$ \\
$\mathbf{4 0 - 6 0}$ & $113(1.07 \%)$ & $28(0.26 \%)$ \\
$>\mathbf{6 0}$ & $36(0.34 \%)$ & $9(0.08 \%)$ \\
Total & $298(2.8 \%)$ & $81(0.8 \%)$ \\
\hline
\end{tabular}

been graded into none, mild, moderate and severe according to this system. However, further systems have come up in this line, namely the Operative Link on Gastritis Assessment (OLGA) system and the Operative Link on Gastric Intestinal Metaplasia Assessment (OLGIM) system that classified the grade and stage of atrophy and intestinal metaplasia respectively. ${ }^{11,12}$ These systems provide better prognostic and management evaluation, as higher stages of intestinal metaplasia and atrophy in the gastric biopsy specimens have higher risk of developing gastric carcinoma later in life. ${ }^{11,12}$ Proposals have been made regarding the frequency of follow up in patients with stage III/IV OLGA/OLGIM groups for early detection and treatment of gastric carcinoma. ${ }^{13-15}$

Hence, AG and IM are specific findings that need to be evaluated in detail. Helicobacter pylori (H. Pylori) which is seen to be commonly found in gastric biopsy is also associated with AG and IM. ${ }^{16,17} \mathrm{H}$. pylori has specific genetic makeup that produces CagA and VacA genes. These genetic groups are seen to have links to $\mathrm{AG}, \mathrm{IM}$ and gastric carcinoma. ${ }^{17-19}$

In this study we are going to evaluate the incidence of AG, IM and H.pylori and their interrelationship with each other. We are also studying their distribution across age and geneder of the study population.

\section{MATERIALS AND METHODS}

It is Cross-sectional study of a retrospectively collected data at KIST medical college and GRP poly clinic private limited of a total of 10,683 cases. Prior to the study, permission was obtained from the Institutional Review Board of KIST Medical College. All the cases from April 2008 till March 2018, of whose slides could be retrieved, were included in the study. Demographic data were retrieved from the medical record. The slides stained with Hematoxilin and Eosin stain and Giemsa stain were evaluated by two pathologist and the findings were entered in Microsoft Excel. Stastiscal analysis of incidence, frequency was calculated using SPSS vs 21. P value was calculated wherever necessary.

\section{RESULTS}

Total number of cases studied was 10,683 . Out of which 5451 $(51.0 \%)$ were male and $5232(49.0 \%)$ were female with male to female ratio of 1.04:1. Mean age of all the cases were 53.2 years. Out of these 10,683 cases, atrophy was seen in $81(0.8 \%)$ cases, Intestinal metaplasia was seen in $298(2.8 \%)$ cases and Helicobacter Pylori was positive in 4459 (42.2\%) cases. Among 10,683 cases, 10,555 were non-neoplatic lesions and were included in the study.

Among male patients who underwent endoscopic biopsy, 39 patients $(0.36 \%)$ had atrophic gastritis whereas 40 female patients $(0.39 \%)$ had atrophic gastritis (Table 1$)$. Incidence of atrophy was insignificant with gender $(p>0.05)$. P value was significant for intestinal metaplasia in male and female $(\mathrm{p}<0.01)$.

The incidence of AG is more in H. pylori positive group $54(0.5 \%)$ compared to $\mathrm{H}$. pylori negative group $(0.25 \%)$. In cases of IM, it is more in $\mathrm{H}$. pylori negative group $190(1.8 \%)$ compared to $\mathrm{H}$. pylori positive cases 108 (1\%) (Table 2). Atrophic gastritis as well as intestinal metaplasia was slightly more frequent among females than in males.

The most common age group in our study population was in 1840 years $(n=6206 ; 58.8 \%)$ followed by $40-60$ years $(n=3202$; $30.3 \%$ ). Mean age of the study population with atrophic gastritis was 40.65 years with minimum of 20 years and maximum age being 84 years. Intestinal metaplasia was most prevalent in the age group of 18-40 years. Atrophic gastritis and Helicobacter were also the most common findings among the same age group (Table 3 ). Atrophy was encountered slightly more among patients below 40 years of age ( 44 vs. 37 cases). (Table 3 )

Intestinal metaplasia was observed across all age groups. The mean age of patients with intestinal metaplasia was 42.21 years 
with youngest being 15 years and oldest 85 years. Seven cases with intestinal metaplasia were observed among patients younger than 19 years, whereas atrophy was not seen in this population. Similarly, intestinal metaplasia was almost equally distributed in the patients below and above 40 years of age (149 cases).

\section{DISCUSSION}

Gastric carcinomas, like most of the other malignancies, have their own risk factors. Particularly well known ones are excessive salt intake, deficient ascorbic acid, insufficient carotene and most importantly H. pylori infections. ${ }^{16}$ In our study the H. pylori incidence was seen in $4475(42.2 \%)$ of cases. In the study done comparing the Japanese and Nepalese population, ${ }^{20}$ 167/309 $(54.0 \%)$ cases were positive for $\mathrm{H}$. pylori and the prevalence did not vary among Aryans and Mongolians. The bacterial virulence genes, cytotoxin-associated gene A [CagA] and vacuolating cytotoxin $\mathrm{A}[\mathrm{VacA}]$, are found to have an important role in the pathogenesis of AG, IM and gastric carcinoma. CagA causes cytoskeletal changes and abnormal gastric epithelial cell proliferation by disrupting the phosphorylation-dependent and independent signaling pathway mechanisms. ${ }^{17}$ VacA has several subtypes (s1-2 and m1-2) unlike CagA . s1m1 is associated with increased epithelial damage, AG and IM. ${ }^{18,19}$ In our study we did not perform any genetic studies due to lack of resources.

There are several types of chronic gastritis and Updated Sydney system classification is the one we widely follow. Histopathologically it takes into consideration activity (neutrophil infiltration), chronic inflammation (mononuclear cell infiltration), glandular atrophy, Intestinal metaplasia and Helicobacter pylori density. The finding are graded into none, mild, moderate and severe using the visual analogue scale. ${ }^{21,22}$ Though widely used, this system does not give the prognosis of gastric cancer risk specially when atrophic gastritis as well as intestinal metaplasia are considered to be precancerous conditions.

Hence new systems were developed namely OLGA (Operative link on Gastritis Assessment) and OLGIM (the Operative Link on Gastric Intestinal Metaplasia Assessment ) systems. According to these systems the patients are grouped into I to IV stages. They provided better management possibility such as OLGA/OLGIM stage III and IV are grouped for secondary preventive surveillance where as stage I and II are exempted from it. ${ }^{11,12,14}$

The incidence of atrophic gastritis, in a meta-analysis including 14 studies, have been shown to be ranging from $0-10.9 \% .{ }^{23}$ The incidence varied according to the clinical set up. Lowest range was seen in patients treated for $\mathrm{H}$. pylori and highest was seen in peptic ulcer disease cases..$^{23}$ In our study the incidence of atrophic gastritis was $81(0.8 \%)$ of case, which is within the above mentioned range. The mean age group for AG in our study population included 18-44 years. Incidence of AG was more in H. pylori positive $54(0.5 \%)$ than negative $27(0.25 \%)$ cases. This finding was similar to the study done by Adamu et al. ${ }^{23}$

The intestinal metaplasia (IM) incidence was more in a $\mathrm{H}$. pylori negative ( $\mathrm{n}=190 ; 1.8 \%$ ) cases compared to positive cases $(\mathrm{n}=108 ; 1 \%)$ in our study. Which was opposite to a study done in Netherlands, in which it was found more in $\mathrm{H}$. pylori positive cases $(33.9 \%)$ than in $\mathrm{H}$. pylori negative cases $(15.2 \%) .{ }^{24}$ The reason for not finding correlation between H. pyori and IM may be due to the fact that environmental or host factors were more important risk factors for IM as some of the studies have reported. ${ }^{25}$ The mean age positive for IM in our study was 42.21 years with a range of 15-85 years, which was lower than the study of Craanen et al, in which it was seen as 64 years of age. ${ }^{24}$ Seven cases of IM were also seen in age lower than 19 years which was seen in atrophic gastritis.

In a study done in Korean population, prevalence of AG ranged from 20.1 to $42.5 \%$ and IM was 21.2 to $28.6 \%{ }^{26}$ This finding was much higher than the one seen in our study. The mean age group for AG was 40.65 years with a range of 20-84 years. AG was almost equally distributed in our study in both male $(0.36 \%)$ and female $(0.39 \%)$ however, in the study done on Korean population it was slightly higher in male $(42.7 \%)$ than female $(38.1 \%){ }^{26}$

Other studies have shown that the incidence of AG and IM increased with age, 27 however in our study we found that both the AG and IM were higher in the age group between 1840 years and it did not show progressive increase in incidence with increasing age. This might be due to the bias created by the maximum number of $(58.8 \%)$ cases in our study coming to the hospital in this age group.

\section{CONCLUSIONS}

Atrophic gastritis and intestinal metaplasia, high-risk factors for gastric carcinoma, were not the common findings. Atrophic gastritis was seen in $0.8 \%$ and intestinal metaplasia was seen in $2.8 \%$ of the total study population. Despite being low in incidence, early detection of these lesions via endoscopy and gastric biopsy can lead to a better management outcome. However, further large scale study and community based study on grading and staging of these precancerous lesions are also required.

\section{ACKNOWLEDGMENT}

Dr Gyanendra Lal Amatya, Consultant Gastroenterologist, GRP poly clinic private limited, Kathmandu.

\section{REFERENCES}

1. Ferlay J, Soerjomataram I, Dikshit R, Eser S, Mathers C, Rebelo $\mathrm{M}$ et al. Cancer incidence and mortality worldwide: sources, methods and major patterns in GLOBOCAN 2012. Int J Cancer. 2015;136(5):E359-86. Crossref

2. Incidence, mortality and Prevalence by cancer site. The global cancer observatory. Globocan 2018 (Cited 15th September 2018) Crossref

3. Incidence, moratlity and Prevalence by cancer site. The global

cancer observatory. Globocan 2018 (Cited 15th Sept 2018) Crossref 4. Yuasa N, Nimura Y. Survival after surgical treatment of early gastric cancer, surgical techniques, and long-term survival. Langenbecks Arch Surg 2005;390:286-93. Crossref

5. Park JM, Ryu WS, Kim JH, Park SS, Kim SJ, Kim CS, et al. Prognostic factors for advanced gastric cancer: stage-stratified analysis of patients who underwent curative resection. Cancer Res Treat 2006;38:13-8. $\underline{\text { Crossref }}$ 
6. Hundahl SA, Phillips JL, Menck HR. The National Cancer Data Base Report on poor survival of U.S. gastric carcinoma patients treated with gastrectomy: fifth edition American Joint Committee on Cancer staging, proximal disease, and the "different disease" hypothesis. Cancer 2000;88:921-32. Crossref

7. Karim-Kos HE, de Vries E, Soerjomataram I, Lemmens V, Siesling S, Coebergh JW. Recent trends of cancer in Europe: a combined approach of incidence, survival and mortality for 17 cancer sites since the 1990s. Eur J Cancer. 2008;44(10):1345-89. Crossref

8. Yoon H, Kim N. Diagnosis and management of high risk group for gastric cancer. Gut Liver 2015;9:5-17. Crossref

9. S, Yamakido M, Taniyama K, Sasaki N, Schlemper RJ. Helicobacter pylori infection and the development of gastric cancer. $\mathrm{N}$ Engl $\mathrm{J}$ Med. 2001;345(11):784-9. Crossref

10. Shiotani A, Haruma K, Uedo N, Iishi H, Ishihara R, Tatsuta M et al. Histological risk markers for non-cardia early gastric cancer. Pattern of mucin expression and gastric cancer. Virchows Arch. 2006;449(6):652-9. Crossref

11. Rugge M, Genta RM. Staging and grading of chronic gastritis. Hum Pathol. 2005;36(3):228-33. Crossref

12. Capelle LG, de Vries AC, Haringsma J, Ter Borg F, de Vries RA, Bruno MJ et al. The staging of gastritis with the OLGA system by using intestinal metaplasia as an accurate alternative for atrophic gastritis. Gastrointest Endosc. 2010;71(7):1150-8. Crossref

13. Dinis-Ribeiro M, Areia M, de Vries AC, Marcos-Pinto R, MonteiroSoares M, O'Connor A at al. European Society of Gastrointestinal Endoscopy; European Helicobacter Study Group; European Society of Pathology; Sociedade Portuguesa de Endoscopia Digestiva. Management of precancerous conditions and lesions in the stomach (MAPS): guideline from the European Society of Gastrointestinal Endoscopy (ESGE), European Helicobacter Study Group (EHSG), European Society of Pathology (ESP), and the Sociedade Portuguesa de Endoscopia Digestiva (SPED). Endoscopy. 2012;44(1):74-94. Crossref

14. Shin WG, Kim HU, Song HJ, et al. Surveillance strategy of atrophic gastritis and intestinal metaplasia in a country with a high prevalence of gastric cancer. Dig Dis Sci. 2012;57(3):746-52. Crossref

15. Fang JY, Du YQ, Liu WZ, Ren JL, Li YQ, Chen XY et al. Chinese Society of gastroenterology. Chinese national consensus on chronic gastritis. Chin J Gastroenterol. 2017;22(11):670-87.
16. Correa P. Human gastric carcinogenesis: a multistep and multifactorial process--First American Cancer Society Award Lecture on Cancer Epidemiology and Prevention. Cancer Res 1992;52:6735-40. $\underline{\text { Crossref }}$

17. Wroblewski LE, Peek RM Jr, Wilson KT. Helicobacter pylori and gastric cancer: factors that modulate disease risk. Clin Microbiol Rev 2010;23:713-39. Crossref

18. Basso D, Zambon CF, Letley DP, Stranges A, Marchet A, Rhead JL et al. Clinical relevance of Helicobacter pylori cagA and VacA gene polymorphisms. Gastroenterology 2008;135:91-9. Crossref

19. Nogueira C, Figueiredo C, Carneiro F, Gomes AT, Barreira R, Figueira $\mathrm{P}$ et al. Helicobacter pylori genotypes may determine gastric histopathology. Am J Pathol 2001;158:647-54. Crossref

20. Matsuhisa T, Miki M, Yamada N, Sharma SK, Shrestha BM. Helicobacter pylori infection, glandular atrophy, intestinal metaplasia and topography of chronic active gastritis in the Nepalese and Japanese population: The age, gender and endoscopic diagnosis matched study. KUM J 2007;5:295-301

21. Misiewicz JJ. The Sydney System: a new classification of gastritis. Introduction. J Gastroenterol Hepatol 1991;6:207-8. Crossref

22. Dixon MF, Genta RM, Yardley JH, Correa P. Classification and grading of gastritis. The updated Sydney System. International Workshop on the Histopathology of Gastritis, Houston 1994. Am J Surg Pathol 1996;20:1161-81. Crossref

23. Adamu MA, Weck MN, Gao L, Brenner H. Incidence of chronic atrophic gastritis: systematic review and meta-analysis of follow- up studies. Eur J Epidemiol 2010;25:439-48. Crossref

24. Craanen ME, Dekker W, Blok P, Ferwerda J, Tytgat GN. Intestinal metaplasia and Helicobacter pylori: an endoscopic bioptic study of the gastric antrum. Gut 1992;33:16-20. Crossref

25. Yo Han Park, Nayoung Kim: Atrophic Gastritis and Intestinal Metaplasia. Journal of Cancer Prevention 2015:20:25-40. Crossref

26. Kim N, Park YS, Cho SI, Lee HS, Choe G, Kim IW, et al. Prevalence and risk factors of atrophic gastritis and intestinal metaplasia in a Korean population without significant gastroduodenal disease. Helicobacter 2008;13:245-55. Crossref

27. Park HK, Kim N, Lee SW, Park JJ, Kim JI, Lee SY, et al. The Distribution of Endoscopic Gastritis in 25,536 Heath Check-up Subjects in Korea. Korean J Helicobacter Up Gastrointest Res 2012;12:237-43. $\underline{\text { Crossref }}$ 